\title{
Edge Effects in Small Forest Fragments: Why More Is Better?
}

\author{
Milind Bunyan ${ }^{1}$, Shibu Jose ${ }^{2}$, Robert Fletcher $^{3}$ \\ ${ }^{1}$ School of Forest Resources and Conservation, University of Florida, Gainesville, USA; ${ }^{2}$ The Center for Agroforestry, School of \\ Natural Resources, University of Missouri, Columbia, USA; ${ }^{3}$ Department of Wildlife Ecology and Conservation, University of Flor- \\ ida, Gainesville, USA. \\ Email: joses@missouri.edu
}

Received May $2^{\text {nd }}, 2012$; revised May $30^{\text {th }}, 2012$; accepted June $9^{\text {th }}, 2012$

\begin{abstract}
Edge to interior gradients in forest fragments can influence the species composition and community structure as a result of variations in microenvironment and edaphic variables. We investigated the response of microenvironment and edaphic variables to distance from a tropical montane forest (locally known as shola)-grassland edge using one-edge and multiple-edge models. The edpahic variables did not show any differences between the grassland and shola soils. We observed that conventional one-edge models sufficiently explained variation trends in microenvironment along the edge to interior gradient in large fragments. As with other studies on small fragments though, we observed no edge effects with the use of a conventional one-edge model. However, the inclusion of multiple edges in small fragments significantly improved model fit. We can conclude that small fragments dominated by edge habitat may in fact resemble larger fragments with the inclusion of multiple edges. Our models did not evaluate non-linear effects which often better explain patterns in edge-interior gradients. The incorporation of such non-linear models in the system might further improve model fit.
\end{abstract}

Keywords: Edge-Interior Gradients; Multiple Edges; Microenvironment; Tropical Montane Forests; Shola-Grassland Ecosystem; Western Ghats; India

\section{Introduction}

The creation of edges in forested habitat poses a significant threat to the ecosystem structure and function. Although initially advocated as an effective technique to increase species diversity [1,2], studies quickly revealed its effect on altered ecological processes [3], species distribution patterns [4] and ecosystem structure [5,6]. The response of microenvironment to edge creation has since been well studied documented across ecosystems [7-9]. Generally speaking, at a newly created edge, increased light transmittance results in elevated levels of air temperature and reduced relative humidity. Soil characteristics are altered too as elevated soil temperatures, nutrient cycling and litter decomposition rates and diminished soil moisture content are seen near edges. Microenvironmental response to edge creation often initiates a series of events that has cascading effects on species distributions and inter-specific interactions as species respond to the altered microenvironmental conditions [10] resulting in a deepening of area under edge influence [6,11]. As fragment size reduces, habitats become increasingly dominated by edge habitat with small frag- ments being characterized as "all edge" [6].

This interaction between fragment size and proportion of habitat under edge influence has been recognized by researchers and studies point to the significance of incorporating multiple edges in edge-effect studies [12]. Conventional edge-effect studies, irrespective of biome, typically consider the effect of distance from the nearest edge (Figure 1). The edge effect $(e)$ at a point $P$ in the patch is a function of the linear distance to edge $\left(d_{1}\right)$. Mathematically,

$$
e(P)=f\left(d_{1}\right)
$$

This offers the least complex framework to demonstrate the response of and interaction between abiotic and biotic response variables to (initially) edge creation and (later) edge habitat. However, this approach limits the extrapolation of edge effects across spatial scales [10]. Conversely, multiple edge-effect studies incorporate estimates of distance to multiple edges and edge effect is measured by:

$$
e(P)=f\left(d_{1}, d_{2} \cdots d_{i} \cdots d_{n}\right)
$$

where $d_{i}$ is a measure of distance to $i$-th edge and $n$ is the 


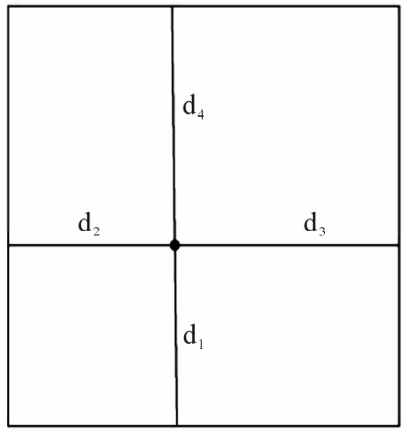

(A)

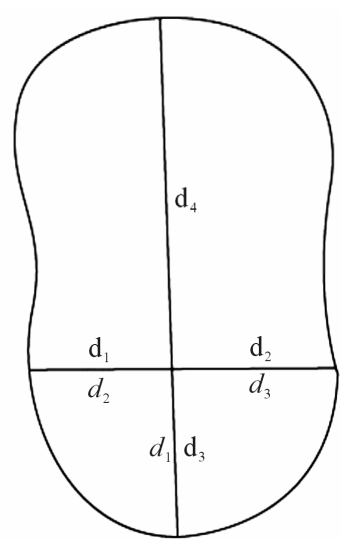

(B)
Figure 1. Schematic representation of estimation of distance to additional edges. (A) $d_{1}, d_{2}, d_{3}$ and $d_{4}$ represent distance estimates to $1^{\text {st }}, 2^{\text {nd }} 3^{\text {rd }}$ and $4^{\text {th }}$ nearest edge. (B) In small fragments, estimated distances to additional edges (gray letters) differed from actual distances (black letters). These distance estimates were revised prior to data analysis. Black dots represent the plot center and $d_{1}-d_{4}$ lines represent distance to nearest, $2^{\text {nd }}, 3^{\text {rd }}$, and $4^{\text {th }}$ nearest edges respectively.

total number of linear edges in a patch. The incorporation of multiple edges has been shown to generate stronger edge effects than models using distance to nearest edge alone. Further these models become increasingly significant in small fragments that may be dominated by edge habitat [6]. However, multiple edge-effects studies continue to be the exception rather than the norm. Large scale manipulative studies on fragmentation and landscape connectivity [Biological Dynamics of Forest Fragment Project (BDFFP), Brazil; Savannah River Site (SRS) Corridor Experiment, South Carolina] too rarely consider the effect of multiple edges (however see Malcolm [7]). This is despite the fact that microenvironmental edge effects have been observed to penetrate as much as $100 \mathrm{~m}$ away from the edge [13].

Despite the small number of multiple-edge studies, there is considerable disparity among the techniques used to investigate the effect of multiple edges on response variables. Fletcher [12] observed that bobolink (Dolichonyx oryzivorus) distributions were influenced by the two nearest edges (D2 model), but the response to these edges was determined by scale considerations (i.e. multiple edge effects were less important at a landscape scale). Mancke and Gavin [14] suggested the use of four orthogonally separated distance-to-edge measures (D4 model) to explain the influence of edges on breeding bird densities. Two other studies [7,15] quantify edge effect at a point $(\mathrm{P})$ within a patch as the integral of all points along the edge which may influence the observed edge effect at P (DMAX model; Figure 1). Of these one uses logistic regression (D2 model) and the others use nonlinear regression (D4 and DMAX models) to model the response of variables to multiple distance-to-edge measures. Given this divergence in modeling approaches, we sought to assess the relative costs (model complexity, number of parameters) and benefits (improvement in model fit) of both multiple-edge and conventional oneedge models.

The study was conducted on a tropical montane forest (TMF)-grassland mosaic in the Western Ghats-Sri Lanka (WGSL) biodiversity hotspot in southern India. TMF (locally and hereafter termed as sholas) are seen at elevations $\geq 1700 \mathrm{~m}$ and consist of insular forest fragments in a matrix of grasslands. Shola fragments are typically small ( $\sim 1 \mathrm{ha})$ and are separated from the surrounding grasslands by a sharp edge which is natural in origin [16]. We tested for gradients in microclimatic and edaphic variables as a function of distance from the shola-grassland edge. Given the preponderance of smaller shola fragments we sought to determine if 1) small fragments were truly "all edge" (which would be indicated by weak or absent edge-interior gradients in response variables) as observed in other studies and 2) if multiple-edge models improved the fit and predictive power of one-edge models. By comparing conventional one-edge models and different multiple edge models, we hope to improve our ability at detecting edge-interior patterns across fragments of different sizes. For the purpose of this study, we restrict comparison of multiple edge-effects models to vector based techniques excluding other raster based approaches. Further in order to disambiguate our use of the term "multiple edges" we refer to multiple edges as edges or boundaries in multiple directions separating a fragment from the surrounding matrix.

\section{Methods}

\subsection{Study Area}

The study area was located in the Western Ghats in southern India. Three study sites were selected that contain representations of the shola-grassland ecosystem; Biligiri Rangaswamy Temple (BRT) Wildlife Sanctuary in the state of Karnataka and Eravikulam National Park and Pampadum shola National Park in the state of Kerala (Figure 2). BRT Wildlife Sanctuary $\left(540 \mathrm{~km}^{2}\right)$, is located at the eastern-most edge of the Western Ghats $\left(11^{\circ} 43^{\prime}\right.$ to $12^{\circ} 08^{\prime} \mathrm{N}$ and $77^{\circ} 0^{\prime}$ to $\left.77^{\circ} 16^{\prime} \mathrm{E}\right)$. Soils in BRT have been classified as Vertisols and Alfisols and described as shallow to moderately shallow with well drained gravelly clay soils on the hills and ridges [17]. BRT is exposed to both southwestern and northeastern monsoons with a dry season from November to May. Rainfall ranges between $898 \mathrm{~mm}$ to $1750 \mathrm{~mm}$ and strong spatial trends have been observed based on topography and altitude [18]. Vegetation in the sanctuary is represented by a diversity of forest types ranging from dry 


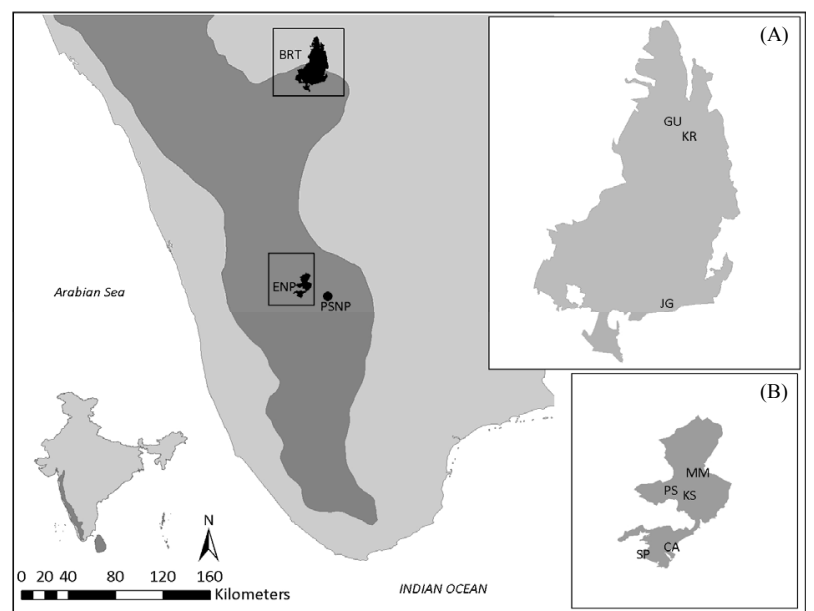

Figure 2. Location of study sites in the Western Ghats. Insular forest fragments were selected from three sites-Biligiri Rangaswamy Temple Wildlife Sanctuary (BRT), Eravikulam National Park (ENP) and Pampadum shola National Park (PSNP). Three fragments were studied in BRT (A), Gummanebetta (GU), Jodigere (JG) and Karadishonebetta (KR). Five fragments were studied in Eravikulam National Park (B), Chinnanaimudi (CA), Kolathan (KS), Mukkal Mile (MM), Pusinambara (PS) and Suicide point (SP). See Table 1 for details on fragments. For inset maps, $1 \mathrm{~cm}$ equals 4 kilometers.

scrub forests to dry and moist deciduous forests, evergreen forests and the high-altitude TMF-grassland (or shola-grassland) ecosystem mosaic. Within BRT, three shola fragments were identified as study sites (Figure 2,

Table 1).

Eravikulam National Park (ENP) is located in the Anaimalai Hills $\left(10^{\circ} 05^{\prime}\right.$ to $10^{\circ} 20^{\prime} \mathrm{N}$ and $77^{\circ} 0^{\prime}$ to $\left.77^{\circ} 10^{\prime} \mathrm{E}\right)$ within the state of Kerala. The park $\left(119 \mathrm{~km}^{2}\right)$ consists of a base plateau at an elevation of $2000 \mathrm{~m}$ surrounded by peaks with a maximum elevation of $2695 \mathrm{~m}$. While the mean maximum temperature recorded in lower elevation tea estates outside ENP varies between $21.9^{\circ} \mathrm{C}$ and $22.7^{\circ} \mathrm{C}$, mean maximum temperature within ENP is as low as $16.6^{\circ} \mathrm{C}$. Similarly, mean minimum temperatures within ENP are lower than those recorded in the tea estates $\left(13.3^{\circ} \mathrm{C}\right)$. The warmest month in ENP is May with a mean maximum temperature of $24.1^{\circ} \mathrm{C}$ and January is the coldest month with a mean minimum temperature $3^{\circ} \mathrm{C}$ (Rice 1984). The soil had been classified as Alfisols and described as Arachean igneous in origin consisting of granites and gneisses [17]. Soils are sandy clay, have moderate depth $(30-100 \mathrm{~cm})$ and are acidic $(\mathrm{ph} 4.1$ 5.3). ENP receives rainfall approximately $5200 \mathrm{~mm}$ of rainfall annually from both the southwest and the northeast monsoon with the former contributing as much as $85 \%$ of the annual rainfall. Although contiguous rainforest formations can also be found at lower elevations, vegetation in the park is predominantly shola-grassland ecosystem mosaic consisting of rolling grasslands interspersed with dense, insular shola fragments. Five shola fragments were selected within ENP (Table 1).

Pampadum shola National Park (PSNP) located within Idukki district in the state of Kerala consists of a large shola patch $\left(1.32 \mathrm{~km}^{2}\right)$ contiguous with lowland forest. Although little is known about this newly notified park (located approximately at $77^{\circ} 15^{\prime} \mathrm{E}$ and $10^{\circ} 08^{\prime} \mathrm{N}$ ) its proximity to the larger Mannavan shola $\left(77^{\circ} 09^{\prime}-77^{\circ} 12^{\prime} \mathrm{N}\right.$ and $10^{\circ} 10^{\prime}-10^{\circ} 12^{\prime} \mathrm{S}$ ) provides insights into broad climatic trends. Mean annual temperature in Mannavan shola has been reported to be approximately $20^{\circ} \mathrm{C}$ with mean minimum temperature in the coldest months (December and January) reaching $5^{\circ} \mathrm{C}$. Mean annual precipitation in Mannavan shola ranges between $2000-3000$ $\mathrm{mm}$. Data from PSNP were collected to compare patterns observed against smaller fragments chosen in BRT and ENP.

\subsection{Sampling Protocol}

To investigate edge-interior gradients in shola fragments,

Table 1. Location of tropical montane forest (shola) fragments across study sites in the Western Ghats, southern India.

\begin{tabular}{ccccccc}
\hline Fragment (shola name) & Fragment code & Study site & Sampling season & Longitude $\left({ }^{\circ}\right.$ E) & Longitude $\left({ }^{\circ} \mathrm{N}\right)$ & Patch area (ha) \\
\hline Karadishonebetta & KR & BRT & Dry & - & - & - \\
Gummanebetta & GU & BRT & Dry & $77^{\circ} 10^{\prime} 38^{\prime \prime}$ & $12^{\circ} 15^{\prime \prime}$ & 1.73 \\
Jodigere & JG & BRT & Dry & $77^{\circ} 11^{\prime} 12^{\prime \prime}$ & $11^{\circ} 47^{\prime} 6^{\prime \prime}$ & 0.20 \\
Suicide point & SP & ENP & Wet & $77^{\circ} 1^{\prime} 33^{\prime \prime}$ & $10^{\circ} 8^{\prime} 23^{\prime \prime}$ & 1.24 \\
Chinnanaimudi & CA & ENP & Wet & $77^{\circ} 3^{\prime} 24^{\prime \prime}$ & $10^{\circ} 9^{\prime \prime} 4^{\prime \prime}$ & 1.66 \\
Kolathan & KS & ENP & Wet & $77^{\circ} 4^{\prime} 31^{\prime \prime}$ & $10^{\circ} 12^{\prime} 57^{\prime \prime}$ & 1.58 \\
Pusinambara & PS & ENP & Wet & $77^{\circ} 43^{\prime \prime}$ & $10^{\circ} 12^{\prime} 56^{\prime \prime}$ & 1.75 \\
Mukkal mile & MM & ENP & Wet & $77^{\circ} 5^{\prime} 7^{\prime \prime}$ & $10^{\circ} 13^{\prime} 51^{\prime \prime}$ & 13.42 \\
Pampadum & PP & PSNP & Wet & $77^{\circ} 15^{\prime} 5^{\prime \prime}$ & $10^{\circ} 7^{\prime} 28^{\prime \prime}$ & 132.00 \\
\hline
\end{tabular}


transects were laid out perpendicular to the shola-grassland edge. Rectangular plots $(10 \times 5 \mathrm{~m})$ were established along these transects with the first plot being established at the edge itself. Plots were laid out with the longer side $(10 \mathrm{~m})$ running parallel to the edge to capture maximum variability along the edge-interior gradient. Successive plots along transects were separated by $5 \mathrm{~m}$ and extended till the middle of the patch or to a distance of $35 \mathrm{~m}$ from the edge, whichever was shorter. This distance was chosen based on past studies that have indicated a leveling off of edge-interior gradients in the shola-grassland Replicate transects within a patch were separated by at least $35 \mathrm{~m}$ though most often greater than $50 \mathrm{~m}$. The number of replicate transects (minimum 1, maximum 4) were determined by the size of the fragment.

\subsubsection{Shola Plots}

Within each $10 \times 5 \mathrm{~m}$ plot, microenvironment and soil variables were measured. Soil temperature was measured using a Barnant ${ }^{\circledR}$ Type $\mathrm{K}$ thermocouple thermometer (BC Group International Inc., St Louis, MO) and air temperature and relative humidity were measured using a digital thermohygrometer (Oakton Instruments, Vernon Hills, IL) held $1.5 \mathrm{~m}$ above the ground. Photosynthetically active radiation (PAR) was measured above and below shola canopy using an AccuPAR LP-80 Ceptometer (Decagon Devices, Pullman, WA). Light transmittance $(\tau)$ was then calculated as the ratio between above and below canopy PAR. Since the shola-grassland ecosystem is characterized by highly variable light environment, above canopy PAR was measured in the adjoining grassland prior to measurement of below canopy PAR in the shola plots. From each $10 \times 5 \mathrm{~m}$ plot, one surface soil $(0-30 \mathrm{~cm})$ sample was collected using a soil corer and immediately double sealed in Ziplock ${ }^{\circledR}$ bags. Soil cores were collected from all but one fragment (Karadishonebetta, BRT). Gravimetric water content was measured by oven-drying soil samples for 24 hours at $105^{\circ} \mathrm{C}$. Soil samples were analyzed for soil organic carbon (WalkleyBlack method), total nitrogen (micro-Kjeldahl distillation method), and extractable phosphorus (Bray-Kurtz method). Available potassium and sodium were estimated using the Flame photometric method. Calcium and Magnesium were estimated by EDTA titration [19]. DTPA extractable iron, manganese, zinc, copper, boron and molybdenum were estimated using an Atomic Absorption Spectrophotometer.

\subsubsection{Grassland Plots}

In four of the shola fragments studied, transects were also established in the grassland to study effects of the sholagrassland edge on the grassland. Since these transects were established as matching pairs to the shola-transects, they originate at the same point as the shola transect with replicate transects at least $35 \mathrm{~m}$ apart. Microenvironment and soil samples were collected and soil samples analyzed using protocols described above from two plots at distances of $5 \mathrm{~m}$ and $15 \mathrm{~m}$ from the shola-grassland edge to test for gradients along grassland-edge-shola interior transects.

\subsection{Data Analysis}

In small forest fragments, it was hypothesized that plots would be influenced by more than one edge. These plots were spatially analyzed using ArcGIS 9.2 (ESRI Labs, Redlands CA) to determine distance to $2^{\text {nd }}, 3^{\text {rd }}$ and $4^{\text {th }}$ nearest edges from each plot (Figure 1). These edges were determined by measuring the distance to the edge in orthogonal directions, thus achieving a measure of distance to edge in each cardinal direction. This approach offers an optimum combination of incorporating information from additional edges while ensuring orthogonal separation [14]. The spatial analysis of additional edges also revealed anomalies in the estimation of distance to the nearest edge in small fragments. In some instances, distances to the edge assumed to be the nearest during data collection would be larger than distances to the 2 nd (on one occasion the 3 rd nearest) edge. Although uncommon, these distance to nearest edge estimates were then revised prior to data analysis (Figure 1(B)). Data obtained from the large shola fragment (PSNP) were also analyzed separately from other fragments in order to test for differences between large and small fragments.

An ANOVA was used to test for differences between shola and grassland microenvironment and soils along grassland-edge-shola interior transects in the fragments $(n=4)$ with both shola and grassland plots. Tukey's HSD was used for multiple comparisons (family-wise error rate $p<0.05)$ to test for differences across the six distance classes (two in the grassland and four in the shola fragments). Additionally, a t-test was used to test for differences in soil microenvironment conditions between grassland and shola soils. For these analyses, soil nutrient concentrations were arcsine-square root transformed in order to achieve normality. A Principal component analysis (PCA) was used to quantify the response of soil nutrient variables to the shola-grassland edge. PCA is often used to define the underlying structure between correlated variables and reduce the number of variables to a smaller number of more meaningful factors and are particularly appropriate when the number of variables is large. Component scores (or loadings) were used to test for a) differences between shola and grassland soils ( $\mathrm{n}=$ 4) using a one-way ANOVA and b) for edge-effects on soil nutrient concentrations (using a simple linear regression) in shola fragments $(\mathrm{n}=8)$.

A regression analysis was used to study the effect of 
the forest (shola)-grassland edge on microenvironment ( $\mathrm{n}$ $=9$ ) and soil variables $(n=8)$ in the sholas. A simple linear regression was also used to quantify the response of microenvironment and edaphic variables as a function of distance from the nearest edge (one-edge model) while a multiple linear regression was used to quantify the effect of multiple (nearest, $2^{\text {nd }}$ nearest, $3^{\text {rd }}$ nearest and $4^{\text {th }}$ nearest) edges on response variables (multiple edge model) in small fragments ( $>1$ ha - 13 ha). Response variables were regressed against distance estimates and log-transformed distance estimates. Log-transformed distance estimates weight plots near edges higher since we have an a priori expectation that edge-interior gradients in shola fragments will be short though sharp. All data analysis was performed using SAS (SAS Institute, Cary $\mathrm{NC}$ ). Given the small sample size we used a conservative estimate of $p=0.05$ in order to reduce Type I errors.

\section{Results}

\subsection{Comparing Shola and Grassland Plots}

Air temperature $(p=0.031)$ and soil temperature $(p<$ $0.020)$ declined significantly along the grassland-edgeshola interior transects (Figure 3). Although grassland plots have significantly lower humidity $(p=0.034)$ than shola plots no gradients were observed along grasslandedge-shola interior transects $(p=0.47)$. Shola and grassland soils differed little in soil nutrients (Table 2) and no trends along the grassland-edge-shola interior transect were observed. The use of principal component analysis (PCA) identified four factors as significant using the latent root criterion (eigenvalue $\geq 1.0$ ) and explained $73 \%$ of the variation (Table 3). A varimax rotation of the selected components was used to maximize orthogonal separation between components and reduce loading of soil nutrients on more than one principal component (or cross-loading). An ANOVA of the selected soil nutrient principal components revealed that on the first principal component (PC1), grassland and shola soils differed marginally $(\mathrm{p}=$ 0.054). Organic carbon and sodium load heavily on PC1 but vary inversely with calcium and magnesium which also load heavily on PC1 (Table 3). None of the other principal components (PC2, PC3 and PC4) varied between habitat type $(p \geq 0.35)$. Further none of the factors varied along the two-sided grassland-edge-shola interior transect $(\mathrm{p} \geq 0.22)$.

\subsection{Microenvironment Gradients in Shola Fragments}

In the large shola fragment (PSNP), relative humidity and soil temperature decreased linearly with increasing distance from edge (Table 4, Figure 4). While relative humidity decreased strongly $(p=0.01)$ with increasing distance from edge and soil temperature decreased strongly

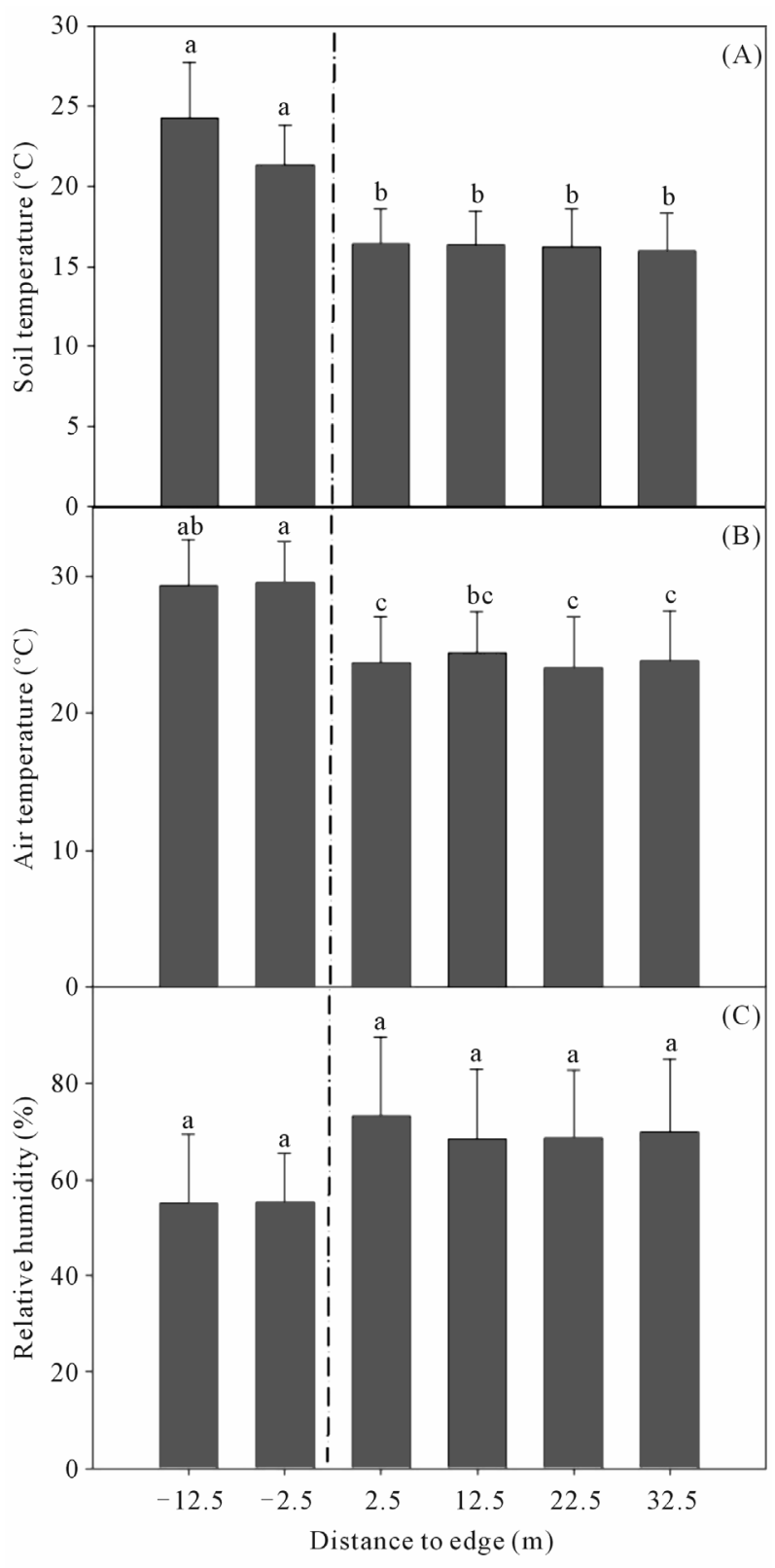

Figure 3. Effect of the shola-grassland edge (dashed line) on microenvironment variables in the shola-grassland ecosystem mosaic. (A) Soil temperature; (B) Air temperature; (C) Relative humidity. Different letters indicate significant differences as determined by Tukey's HSD comparison ( $p<$ 0.05). Error bars represent one standard error.

weakly $(p=0.06)$, no trends were observed in air temperature $(p=0.74)$ and light transmittance $(p=0.79)$. However, light transmittance decreased to $3( \pm 0.3) \%$ of overstory light conditions within $5 \mathrm{~m}$ of the edge. Although most soil nutrients did not vary as a function of distance from the nearest edge, available potassium increased $(p=0.0089)$ with increasing distance from edge (Table 3, Figure 4). Contrary to other studies that have reported strong non-linear relationships in soil variables 
Table 2. Plant-essential nutrient concentrations in tropical montane forest and grassland surface soils in the Western Ghats, southern India. Values are means $( \pm 1 \mathrm{SE})$ expressed as $\mathrm{g} \cdot \mathrm{kg}^{-1}$ unless noted otherwise.

\begin{tabular}{ccc}
\hline Soil nutrient parameter & Shola & Grassland \\
\hline Macronutrients & $6.49^{*}(0.216)$ & $7.45^{*}(0.26)$ \\
Soil moisture (\%) & $19.30^{*}(0.51)$ & $17.23^{*}(1.0)$ \\
Soil organic carbon & $0.53(0.01)$ & $0.55(0.02)$ \\
Nitrogen & $0.144(0.004)$ & $0.143(0.006)$ \\
Phosphorous & $0.135(0.0003)$ & $0.133(0.007)$ \\
Potassium & $0.139(0.003)$ & $0.145(0.005)$ \\
Calcium & $0.142(0.003)$ & $0.134(0.007)$ \\
Magnesium & & $0.124(0.004)$ \\
Micronutrients & $0.121(0.002)$ & $0.0058(0.0003)$ \\
Iron & $0.0057(0.0001)$ & $0.00014(0.00002)$ \\
Boron & $0.00013(0.000005)$ & $0.050(0.002)$ \\
Manganese & $0.048(0.001)$ & $0.000061(0.000003)$ \\
Zinc & $0.000056(0.000002)$ & $0.000134(0.00001)$ \\
Copper & $0.000138(0.000005)$ &
\end{tabular}

Table 3. Principal components scores for soil variables in tropical montane forest fragments and grassland soils in the Western Ghats (eigenvalue $\geq 1$ ). Bold values indicate the component on which the variable loads after a varimax rotation was applied.

\begin{tabular}{ccccc}
\hline Variable & PC1 & PC2 & PC3 & PC4 \\
\hline Eigenvalue & 2.6339 & 1.7456 & 1.5472 & 1.1782 \\
Proportion variance explained & 0.2634 & 0.1746 & 0.1547 & 0.5927 \\
Cumulative variance explained & - & 0.4380 & 0.5927 & 0.7105 \\
OGC & 0.8230 & -0.2062 & 0.2420 & -0.1481 \\
NIT & -0.2197 & 0.8292 & -0.0645 & -0.0431 \\
PHO & -0.0569 & 0.7863 & 0.1720 & 0.3743 \\
POT & -0.1527 & 0.0845 & -0.0660 & 0.8147 \\
CAL & -0.6289 & 0.0689 & 0.5139 & 0.2867 \\
MAG & -0.7399 & -0.0993 & 0.3650 & -0.311 \\
SOD & 0.6805 & -0.1299 & 0.1163 & -0.1697 \\
MAN & 0.0357 & 0.6671 & 0.1054 & -0.5675 \\
MOL & 0.0254 & 0.1001 & 0.8919 & 0.0920 \\
COP & -0.0454 & 0.0006 & -0.6009 & 0.2412 \\
\hline
\end{tabular}

OGC: Organic carbon, NIT: Total Nitrogen, PHO: Available phosphorous, POT: Potassium, CAL: Calcium, MAG: Magnesium, SOD: Sodium, MAN: Manganese, MOL: Molybdenum, COP: Copper.

[6], we found no evidence of non-linearity. Adding a quadratic (distance to nearest edge) term did not significantly improve the fit of relative humidity $(p=0.018)$ and reduced the significance of estimates of available potassium $(\mathrm{p}=0.030)$ and other significant variables $(\mathrm{p} \geq$
0.101). A factor analysis of soil nutrient variables with quartimax rotation for PSNP soils revealed two factors as significant that explained $72 \%$ of the variation (data not presented). While the first factor loads heavily on organic carbon, total nitrogen, available phosphorous and calcium, 


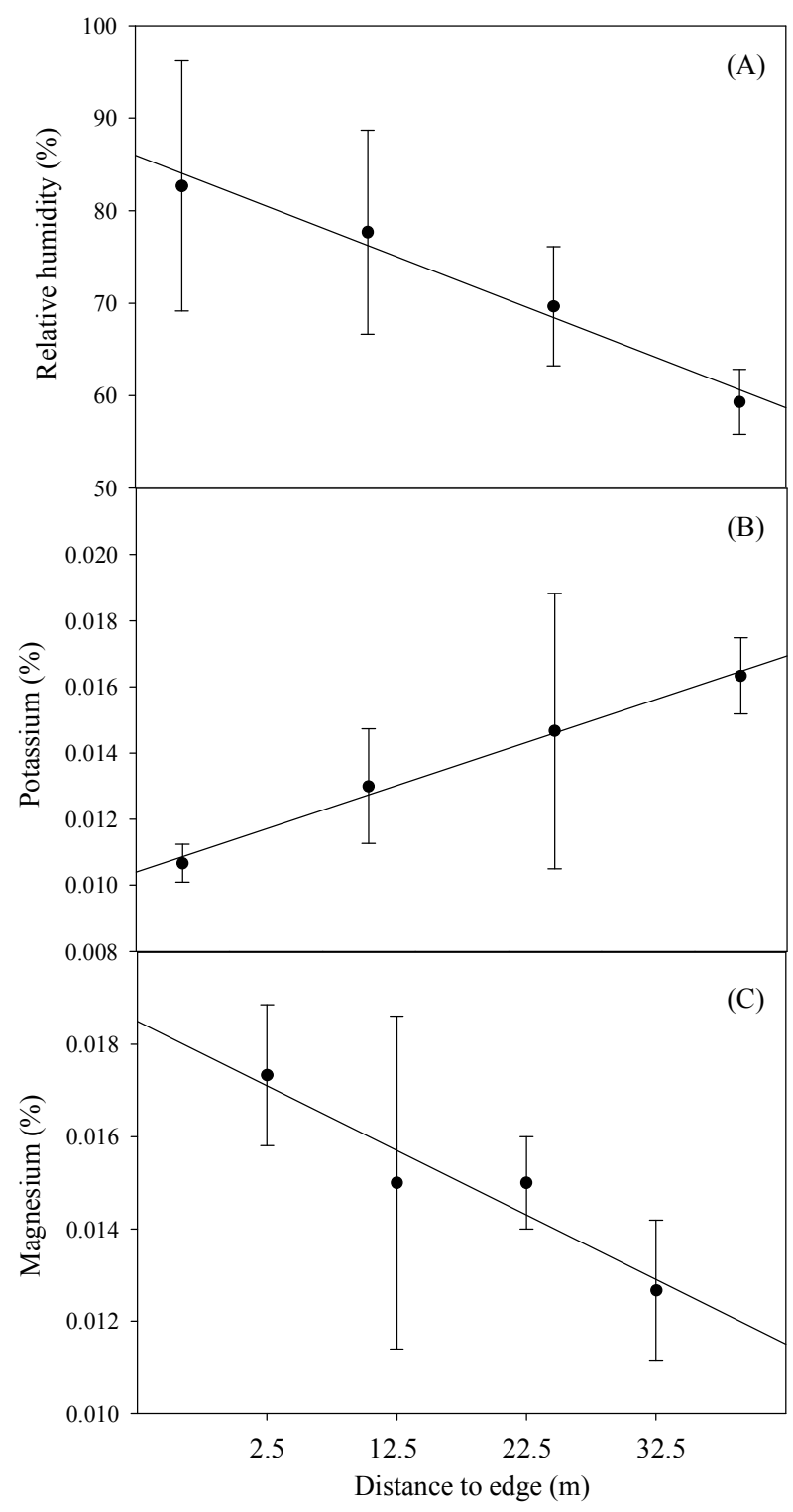

Figure 4. Edge-interior gradients in mi-croenvironment and soil nutrient parameters in Pampadum shola National Park ( 132 ha). Error bars represent one standard error.

the second factor loads heavily on manganese. However a linear regression of factors against both factors did not vary with distance from the nearest edge $(p \geq 0.13)$.

Small forest fragments though showed no trends in microenvironment (air temperature, relative humidity, light transmittance) or soil variables (soil temperature, macronutrient and micronutrient concentrations) as a function of distance of nearest edge (single edge model). Responses were weaker still when log-distances were used $(p \geq 0.242)$. The incorporation of information through distance estimates for additional $\left(2^{\text {nd }}, 3^{\text {rd }}\right.$ and $4^{\text {th }}$ nearest) edges through the multiple edge model resulted in a significant improvement of the regression models. With increasing distance from edge, significant patterns were observed as air temperature $(p=0.0320)$ and light transmittance $(\mathrm{p}=0.0072)$ decreased. Weaker trends were observed with relative humidity increasing and soil temperature decreasing with increasing distance from edge (Table 4). Soil macronutrient variables were not correlated with edge distance using either the one-edge or multiple edge models. Factor analysis of soil nutrient variables produced three factors (and explained 55\%) of the variation). Again, none of these factors were correlated with either the one-edge or multiple edge models. A canonical correlation was also used to test all soil nutriaent variables against all distances in order to test for correlations between the variables. However, the analysis failed to find any significant correlations.

\section{Discussion}

The microenvironment in grasslands was significantly different from that of shola fragments. However, no significant differences were observed between grassland and shola fragment soils. Similar trends in soil response variables have been reported by other authors too [20, 21]. Our estimates for soil nutrient variables for sholas and grasslands are comparable to others from the ecosystem mosaic [22]. However, significantly higher estimates for soil organic carbon and soil moisture have also been reported from the ecosystem mosaic [20]. Factor analysis of soil variables indicates that soil organic carbon and calcium load had positive and negative loading on the first factor (which explained $20 \%$ of the variation in the dataset). This is typical of forest soils that have higher soil organic carbon while basic cations $\left(\mathrm{Ca}^{2+}\right)$ are lower (as they are lost to leaching) than grassland soils.

Although two-sided edges are less investigated, their proportion vis-à-vis one sided edge studies has increased considerably [23]. Their relevance to matrix-based approaches to understanding edge-effects and restoration ecology is also being increasingly recognized [10,23,24]. This could be significant in the shola-grassland ecosystem mosaic where the matrix surrounding forest fragments (typically grassland), has been shown to be hostile to animal taxa $[25,26])$. In our study I found evidence of two-sided edges in microenvironment response variables. However this pattern was absent in soil response variables with the exception of weak trends in soil organic carbon. Information on two-sided edges in the sholagrassland ecosystem mosaic can also assist in ecosystem restoration efforts by providing requisite conditions for re-establishment of shola fragments in areas converted to exotic tree plantations.

Soils in the shola-grassland ecosystem mosaic had high levels of DTPA extractable iron. Although much higher than another estimate from the mosaic [21] it is comparable to those observed from TMF-grassland edge 
Table 4. Edge-interior gradients in tropical montane forest (shola) fragments in the Western Ghats, southern India. Small fragments $(n=7)$ varied between $0.2-13$ ha whereas the large fragment $(n=1)$ was 132 ha.

\begin{tabular}{|c|c|c|c|c|c|c|}
\hline \multirow{3}{*}{ Variable } & \multicolumn{6}{|c|}{ Fragment size } \\
\hline & \multicolumn{3}{|c|}{ Large } & \multicolumn{3}{|c|}{ Small } \\
\hline & Predictor variables & $\mathrm{r}^{2}$ & $\mathrm{p}$ & Predictor variables & $r^{2}$ & $\mathrm{p}$ \\
\hline Air temperature $\left({ }^{\circ} \mathrm{C}\right)$ & & 0.017 & 0.7492 & logdist, logdist2 & 0.174 & 0.0320 \\
\hline Relative humidity (\%) & logdist & 0.443 & 0.0181 & & 0.142 & 0.0625 \\
\hline Light transmittance (\%) & & 0.006 & 0.7978 & logdist, logdist2 & 0.268 & 0.0072 \\
\hline Soil temperature $\left({ }^{\circ} \mathrm{C}\right)$ & & 0.302 & 0.0637 & & 0.180 & 0.0695 \\
\hline Total nitrogen & & 0.010 & 0.7568 & & 0.0637 & 0.1068 \\
\hline Magnesium & logdist & 0.3990 & 0.0276 & & 0.002 & 0.7418 \\
\hline Potassium (\%) & logdist & 0.511 & 0.0089 & & 0.007 & 0.5864 \\
\hline Soil moisture (\%) & & 0.001 & 0.8993 & dist, dist2 & 0.427 & 0.0002 \\
\hline Avail. Phosphorous (\%) & & 0.316 & 0.0570 & & 0.114 & 0.1979 \\
\hline Calcium & & 0.067 & 0.4149 & & 0.114 & 0.3305 \\
\hline
\end{tabular}

Significant relationships are in bold $(\mathrm{p}<0.05)$, number of predictor variables used in the model was chosen based on Akaike information criterion $($ AIC). Predictor variables are only displayed for significant models.

in Sri Lanka experiencing dieback [27]. Although Ranasinghe et al. [27] suggested that the dieback of TMF could be related to iron toxicity induced diminished nitrogen absorption for soils with iron levels that are higher (200 - 400 ppm). I did not observe such high levels of DTPA extractable iron in our study. However, unlike TMF-grassland soils in Sri Lanka, shola fragment and grassland soils alike did not record high DTPA extractable manganese or copper levels.

Large shola fragments exhibit different patterns from smaller shola fragments. In Pampadum shola distance from the nearest edge was sufficient to explain trends in microenvironment and edaphic variables. However, distance from the nearest edge could not sufficiently explain the soil variables.

\subsection{Seasonal and Diurnal Variation}

Since individual transects were sampled over the course of a single day, a diurnal variation in relative humidity and air temperature can be expected. As the day progresses, ambient air temperatures would increase leading to a lowering of relative humidity. An inverse relationship between relative humidity and air temperature, it can be argued, could be an artifact of either distance from the forest fragment (shola)-grassland edge or diurnal variation. However, in our study, air temperature and relative humidity were not inversely related. In smaller fragments, we did indeed observe such trends (air temperature decreased with increasing distance while relative humidity increased). However in the large fragment (PSNP), relative humidity decreased with increasing distance from edge (and as the day progressed) while air temperature showed no edge-interior trends. Such changes in relative humidity trends as a function of distance from the edge could also be an artifact of seasonality. Sampling of the large fragment (PSNP) was done in the wet season and often under constant cloud cover leading to higher relative humidity near the shola-grassland edge and lower humidity inside (Figure 4). Since the sampling of small fragments was carried out in both wet and dry seasons, trends are more intuitive (increasing humidity with increasing distance from edge) albeit weakened by wet season data.

Our estimate of light transmittance (3\% of overstory light conditions) is significantly lower than light transmittance at the edge (12\%) reported by Jose et al. [8] although similar to estimates from old growth rainforest-pasture edges in Mexico (4.7\%) [9]. Other studies too have reported an abrupt change in light conditions across a high contrast edge [28]. Shola fragments thus represent deeply shaded habitats and low depth of influence (DEI) with regard to light transmittance. Analysis of the large shola fragment (PSNP) revealed trends (although weak) widely reported from other edge-effect studies (e.g. soil temperature) both in tropical montane forests and lowland tropical forests $[8,13]$.

\subsection{Comparison between One-Edge and Multiple Edge Models}

Studies on edge-effects across biomes have demonstrated the effect of distance from edge on microenvironment and edaphic variables. In tropical forests, edge effects have been particularly worrisome as microenvironment gradients extend as much as $100 \mathrm{~m}$ away from the edge 
of forested habitat [13]. As a corollary to this, smaller fragments have been hypothesized to be dominated by edge habitat [6]. Most studies in tropical fragments though measure the response variables as a function of distance from nearest edge and do not incorporate the effect of distance from additional edges (however, see [7]). In the shola-grassland ecosystem mosaic, large shola fragments exhibited different patterns from smaller shola fragments. In Pampadum shola distance from the nearest edge was sufficient to explain trends in microenvironment and edaphic variables. However in smaller forest fragments, microenvironment and edaphic variables did not show a response with distance from the nearest edge suggesting that fragments are dominated by edge habitat. However, the incorporation of additional edges as predictor variables in the model significantly improved model fit. Moreover multiple edge-models were more parsimonious (lower AIC values) than one-edge models (Table 4). To our knowledge, no other studies from the shola-grassland ecosystem or from other tropical montane forest fragments have tested for multiple edge effects. The incorporation of multiple edge-effect models might better explain the absence of edge interior gradients in other edge effect studies also [9].

Delineating edges and determining edges using spatial analysis techniques may not always be feasible though. In our study, insular forest fragments are isolated from other forest types by a high contrast grassland edge. This made determination of distance to additional edges relatively easy. When edges separate similar habitat types (such as a native forest-tree plantation edge) distinguishing habitat types might require the use of other techniques (landcover/landuse classification).

\section{Conclusion}

The present study describes the response of microenvironment and edaphic variables to distance from a tropical montane forest (shola)-grassland edge. Nutritionally, grassland and shola soils differed little. Since such results have been consistently observed across multiple study sites in the ecosystem mosaic, an edaphically controlled shola-grassland edge appears unlikely. The influence of other driving variables such as fire or frost needs further investigation. We observed that conventional one-edge models sufficiently explained variation trends in microenvironment variables along the edge-interior gradient in large fragments. As with other studies on small fragments though, we observed no edge effects with the use of a conventional one-edge model. However, the inclusion of multiple edges in small fragments significantly improved model fit. We can conclude that small fragments observed to be dominated by edge habitat may in fact resemble larger fragments with the inclusion of mul- tiple edges. Our models did not evaluate non-linear effects which often better explain patterns in edge-interior gradients. The incorporation of such non-linear models in the system might further improve model fit. Finally, further research is required in investigating the effect of multiple edge models in predicting edge effects across fragment sizes, edge types and biomes in order to improve our understanding of edge effects.

\section{REFERENCES}

[1] A. Leopold, “Game Management," Scribner Sons, New York, 1993.

[2] V. R. Johnston, "Breeding Birds of the Forest Edge in Illinois," Condor, Vol. 49, No. 2, 1947, pp. 45-53. doi: $10.2307 / 1364118$

[3] J. E. Gates and L. W. Gysel, "Avian Nest Dispersion and Fledgling Success in Field-Forest Ecotones," Ecology, Vol. 59, No. 5, 1978, pp. 871-883. doi:10.2307/1938540

[4] S. H. Anderson, K. Mann and H. H. Shugart, "The Effect of Transmission-Lines Corridors on Bird Populations," American Midland Naturalist, Vol. 97, No. 1, 1977, pp. 216-221. doi: $10.2307 / 2424698$

[5] W. F. Laurance, L. V. Ferreira, J. M. Rankin-De Merona, S. G. Laurance, R. W. Hutchings and T. E. Lovejoy, "Effects of Forest Fragmentation on Recruitment Patterns in Amazonian Tree Communities," Conservation Biology, Vol. 12, No. 2, 1998, pp. 460-464. doi:10.1046/j.1523-1739.1998.97175.x

[6] C. G. Gascon, B. Williamson and G. A. B. da Fonseca, "Receding Forest Edges and Vanishing Reserves," Science, Vol. 288, No. 5470, 2000, pp. 1356-1358. doi: $10.1126 /$ science. 288.5470 .1356

[7] J. R. Malcolm, "Edge Effects in Central Amazonian Forest Fragments," Ecology, Vol. 75, No. 8, 1994, pp. 24382445. doi: $10.2307 / 1940897$

[8] S. Jose, A. R. Gillespie, S. J. Goerge and M. K. Kumar, "Vegetation Response along Edge-Interior Gradients in a High Altitude Tropical Forest in Peninsular India," Forest Ecology and Management, Vol. 87, No. 1-3, 1996, pp. 51-62. doi:10.1016/S0378-1127(96)03836-4

[9] G. Williams-Linera, V. Domínguez and M. E. GarciaZurita, "Microenvironment and Floristics of Different Edges in a Fragmented Tropical Rainforest," Conservation Biology, Vol. 12, No. 5, 1998, pp. 1092-1102. doi:10.1046/j.1523-1739.1998.97262.x

[10] L. Ries, R. J. Fletcher and J. Battin, "Ecological Responses to Habitat Edges: Mechanisms, Models and Variability Explained," Annual Review of Ecology Evolution and Systematics, Vol. 35, 2004, pp. 491-522. doi:10.1146/annurev.ecolsys.35.112202.130148

[11] K. A. Harper and S. E. MacDonald, "Structure and Composition of Edges Next to Regenerating Clear-Cuts in Mixed-Wood Boreal Forest," Journal of Vegetation Science, Vol. 13, No. 4, 2002, pp. 535-546. doi:10.1111/j.1654-1103.2002.tb02080.x

[12] R. J. Fletcher, "Multiple Edge Effects and Their Implica- 
tions in Fragmented Landscapes," Journal of Animal Ecology, Vol. 74, No. 2, 2005, pp. 342-352. doi:10.1111/j.1365-2656.2005.00930.x

[13] W. F. Laurance, T. E. Lovejoy, H. L. Vasconcelos, E. M. Bruna, R. D. Didham, P. C. Stouffer, C. Gascon, R. O. Bierregaard, S. G. Laurance and E. G. Sampaio, "Ecosystem Decay of Amazonian Forest Fragments: A 22Year Investigation," Conservation Biology, Vol. 16, No. 3, 2002, pp. 605-618. doi:10.1046/j.1523-1739.2002.01025.x

[14] R. G. Mancke and T. A. Gavin, "Breeding Bird Density in Woodlots: Effects of Depth and Buildings at the Edges," Ecological Applications, Vol. 10, 2000, pp. 598611. doi:10.1890/1051-0761(2000)010[0598:BBDIWE]2.0.C $\underline{\mathrm{O} ; 2}$

[15] C. Fernández, F. J. Acosta, G. Abellá, F. López and M. Díaz, "Complex Edge Effect Fields as Additive Processes in Patches of Ecological Systems," Ecological Modelling, Vol. 149, No. 3, 2002, pp. 273-273. doi:10.1016/S0304-3800(01)00464-1

[16] R. Sukumar, H. S. Suresh and R. Ramesh, "Climate Change and Its Impact on Tropical Montane Ecosystems in Southern India," Journal of Biogeography, Vol. 22, 1995, pp. 533-536. doi:10.2307/2845951

[17] NATMO (National Atlas and Thematic Mapping Organization), "Soil Map of India," 2009, Last Accessed on 4 May 2009. www.indiabiodiversity.org

[18] J. Krishnaswamy, M. C. Kiran and K. N. Ganeshaiah, "Tree Model Based Eco-Climatic Vegetation Classification and Fuzzy Mapping in Diverse Tropical Deciduous Ecosystems Using Multi-Date NDVI," International Journal of Remote Sensing, Vol. 25, No. 6, 2005, pp. 1185-1205. doi:10.1080/0143116031000149989

[19] S. E. Allen, "Chemical Analysis of Ecological Materials," Blackwell Scientific, Oxford, 1974.

[20] S. Jose, A. Sreepathy, B. Mohan Kumar and V. K. Venugopal, "Structural, Floristic and Edaphic Attributes of the Shola-Grassland Forests of Eravikulam in Peninsular India," Forest Ecology and Management, Vol. 65, 1994, pp. 279-291. doi:10.1016/0378-1127(94)90176-7
[21] V. Nandakumar, P. Rajendran and K. Narendra Babu, "Characterization of Soils in the Sholas of Idukki and Wayanad Districts," In: K. K. N. Nair, S. K. Khanduri and K. Balasubramanayam, Eds., Shola forests of Kerala: Environment and Biodiversity, Kerala Forest Research Institute, Peechi, 2001, pp. 25-70.

[22] T. P. Thomas and S. Sankar, "The Role of Sholas in Maintaining Watercourses in the High Ranges of Kerala," In: K. K. N. Nair, S. K. Khanduri and K. Balasubramanayam, Eds., Shola forests of Kerala: Environment and Biodiversity, Kerala Forest Research Institute, Peechi, 2001, pp. 71-115.

[23] C. R. Fonseca and F. Joner, "Two Sided Edge Effect Studies and the Restoration of Endangered Ecosystems," Restoration Ecology, Vol. 15, No. 4, 2007, pp. 613-619. doi:10.1111/j.1526-100X.2007.00273.x

[24] L. Ries and T. D. Sisk, "A Predictive Model of Edge Effects," Ecology, Vol. 85, No. 11, 2004, pp. 2917-2926. doi:10.1890/03-8021

[25] K. Shanker, "The Role of Competition and Habitat in Structuring Small Mammal Communities in a Tropical Montane Forest Ecosystem in Southern India," Journal of Zoology, Vol. 253, No. 1, 2001, pp. 15-24. doi:10.1017/S0952836901000024

[26] A. A. Zarri, A. R. Rahmani, A. Singh and S. P. S. Khushwaha, "Habitat Suitability Assessment for the Endangered Nilgiri Laughing Thrush: A Multiple Logistic Regression Approach," Current Science, Vol. 94, No. 11, 2008, pp. 1487-1494.

[27] P. N. Ranasinghe, C. B. Dissanayake, D. V. N. Samarasinghe and R. Galappatti, "The Relationship between Soil Geochemistry and Die Back of Montane Forests in Sri Lanka: A Case Study," Environmental Geology, Vol. 51, No. 6, 2007, pp. 1077-1088. doi:10.1007/s00254-006-0399-6

[28] F. López-Barrera, A. Newton and R. Manson, "Edge Effects in a Tropical Montane Forest Mosaic: Experimental Tests of Post-Dispersal Acorn Removal," Ecological Research, Vol. 20, No. 1, 2005, pp. 31-40. doi:10.1007/s11284-004-0016-7 